\title{
Calculation and Analysis of the Loads of Dou-Gong Brackets on Ming Dynasty Wooden Buildings in China
}

\author{
Chengya ZHANG, Yubo GAO*, Enze DUAN
}

\begin{abstract}
Constructions of Chinese ancient wooden buildings not only perform a seismic behavior but also benefit stability of the whole structures under static loads to protect Chinese ancient wooden buildings. Based on the surveying and mapping of JinciMirror Terrace and the collected data, load on the Mirror Terrace is calculated to provide the accurate value of the load, which can be used to determine the repair plan and provide a reference for later calculation of similar ancient buildings. The static stability is analyzed to determine whether the main components of the Mirror Terrace have good performance, discover the structural ideas of the ancients during construction, and provide a basis for the protection and maintenance of the buildings
\end{abstract}

Keywords: ancient building; internal force; load range; Ming dynasty; static load

\section{INTRODUCTION AND RESEARCH AIM}

There has been a problem in the ancient building that detailed and exact data on the weight of ancient building roofs is lacking. This brought certain difficulties to the structural design and cultural relics repair work [1]. Without accurate data, the value of the roof load is determined by experience during structural design, which will inevitably cause the waste or lack of structural component materials. For the repair of cultural relics and ancient buildings, accurate data is needed to determine the repair plan.

For modern wooden structures, a lot of research has been done on the loads acting on the structure and the material strength, and the corresponding codes have been formed $[2,3]$. However, the load research on ancient buildings is not complete. First, it is difficult to apply the unified code due to the different roof types, beam distribution and material grades of the ancient buildings. Second, the design base period has been stipulated for 50 years, which is obviously not suitable for ancient buildings, so the load for repair and reinforcement of ancient buildings cannot be calculated according to this code [4].

Many scholars have conducted theoretical and experimental research on the seismic performance of ancient buildings [5-7]. Some scholars have conducted research on the conservation of ancient building [8]. Zhou Qian discussed the static stability of Taihe Palace in Forbidden City [9]. The calculation of ancient building loads is described in more detail in Wang Tian's research [10]. Based on Song's YingzaoFashi, the load weight is related to the Cai-fen system, including the calculation of the dead weight of the roof, the weight of the timber frame, and the live load; In the Compilation of Roof Loads of Ancient Buildings, Liu Dake [1] applied the official practices of the Qing Dynasty to classify the weight of the Tile roof and other components such as the weight of the Chih-Wei; Dong Xufen [4] discussed determination of the load value of the ancient building and determination of the design reference period and discussed the effects of the permanent action and the variable action on the ancient building, respectively. Wang Jiansheng calculated the structural characteristics and the bending moment shear force of beams and columns of an antique building in a certain Shaolin hall [11]. It can be seen that although the predecessors had systematic research and analysis in calculation of the ancient building loads, they only started from the perspective of official practice $[12,13]$ and their content is also based on the calculations made by the official method that are more applicable to official buildings and the load calculation and analysis of nonofficial buildings are lacking. The unit of the Caifen system is still used. Although the calculation process is simplified, the data is not intuitive in actual application and secondary conversion is required.
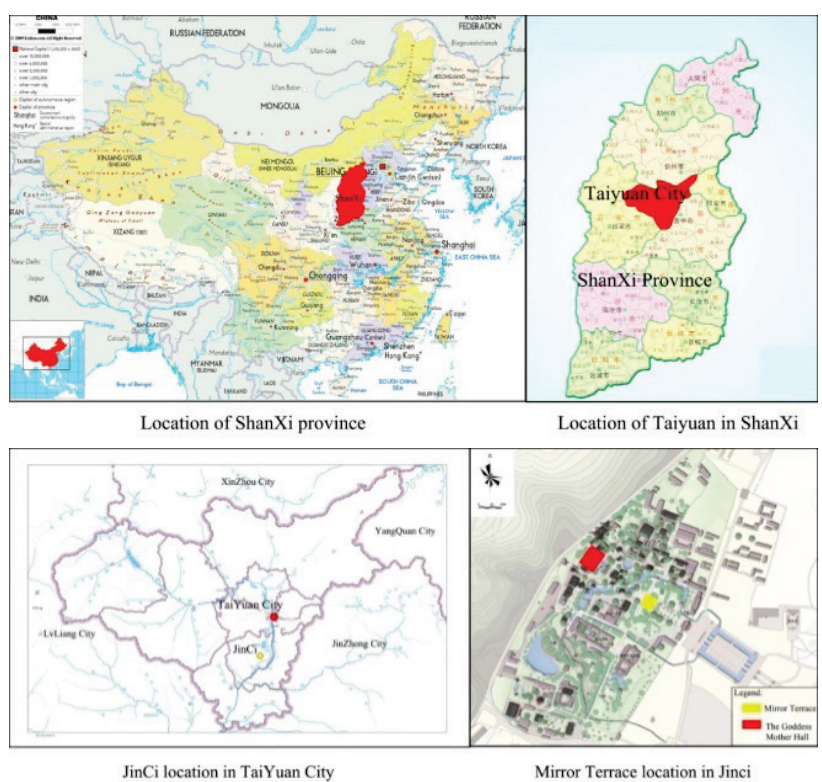

Figure 1 Mirror Terrace Location Map

This load calculation analysis selects Jinci Mirror Terrace as the research object. Mirror Terrace is located in Jinci Town, Jinyuan District, Taiyuan City, Shanxi Province. The Mirror Terrace, as shown in Fig. 1, is a function of the God of Reward. It is a typical opera stage in the Ming dynasty. The water mirror stage sits east to west and the stage is inverted. The plane is approximately square. It is built on a platform about 1.4 meters in height. It is tandem in front and back. It has a nine-ridge doubleeaves roof in the backstage and a single roll eaves roof in the front. Plane construction with large eaves and reduced 
columns effectively enhances the viewing effect. It has typical theater building characteristics (Fig. 2). Mirror Terrace meets the needs of the opera, that is, the front desk is used for performance and the backstage is used for makeup and dressing.

The west side of the Mirror Terrace is the frontage, with three rooms wide, four rafters in-depth and a single eaves roll roof. The east side of the Mirror Terrace is the backstage called Musical Pavilion. It is three widths and two depths, with corridors. The peristyle columns are covered with lintels and plates.

The round ridge single-eave roof structure combined with the gable and hip double-eave is a unique example of the roof structure for the stage building, with rich shapes and reflects the exquisite and unique architectural structure of the Song dynasty [14].

Due to the natural forces and man-made damages, these existing ancient wooden structures are damaged. It is urgent to carry out an investigation of the status and evaluate its stability and safety and its maintenance requires detailed and accurate load data. Therefore, this article combines the knowledge of ancient building statics with the actual component size and materials used in the Mirror Terrace to calculate the load on the brackets in different parts of the building, so as to provide reliable information for the protection and repair of the MirrorTerrace.

\section{METHODOLOGIES}

The features of the ancient building are concentrated on its roof. Under the support of the square rafters (Fei) and rafters, the eaves of the ancient building are far-reaching [15]. Detailed structures determine that the load components of ancient buildings are more complicated.

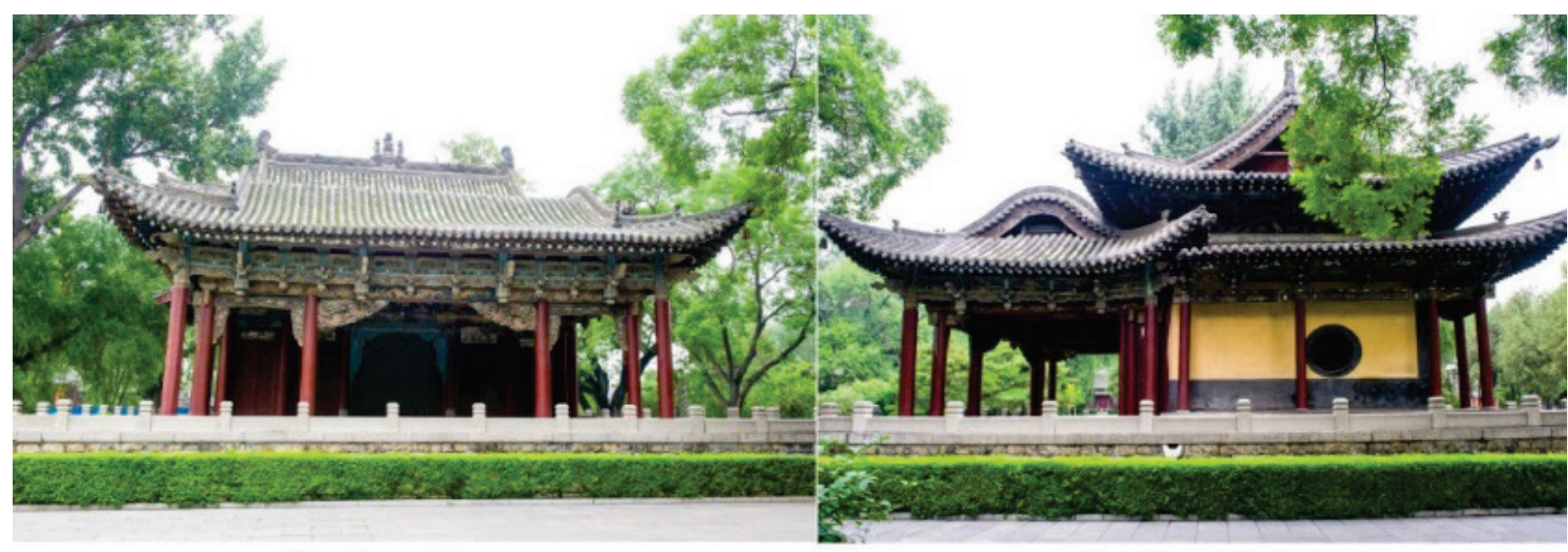

Mirror Terrace frontage

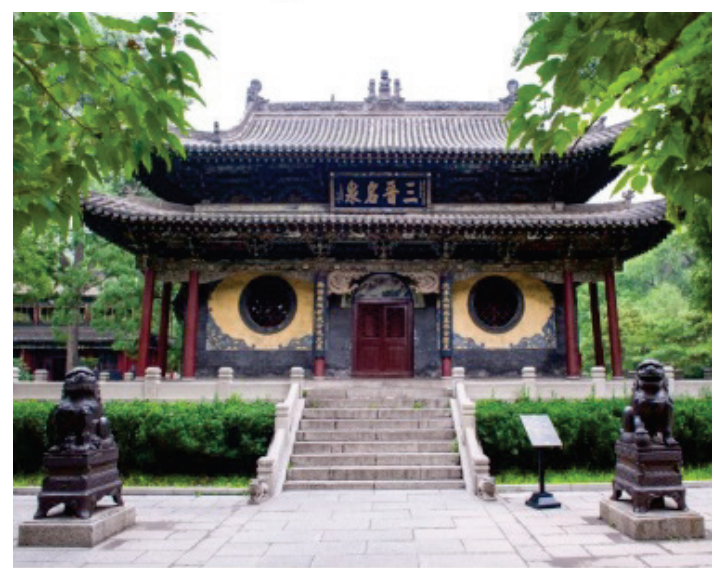

Mirror Terrace backstage
Mirror Terrace Side elevation

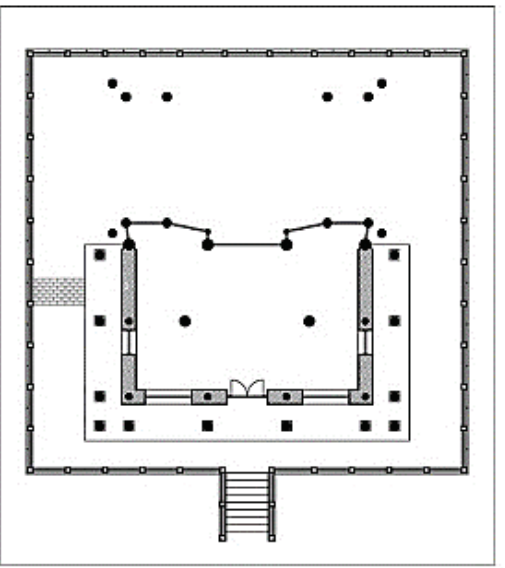

Mirror Terrace plan shape

Figure 2 Mirror Terrace

The load of ancient wooden structures includes three parts: the dead weight of the roof, the dead weight of the wooden frame and the live load. The calculated load mainly calculates the dead weight of the roof and the dead weight of the wooden frame. Some sporadic components were discarded [16]. Live loads are estimated with reference to modern building load codes. The live load on the roof is $30 \mathrm{~kg} / \mathrm{m}^{2}$; the live load on the hidden floor is 150 $\mathrm{kg} / \mathrm{m}^{2}$.

The weight of the upper eaves and beams of the Mirror Terrace is mainly transmitted by the purlins to the second- floor Dou-gong brackets and then to the columns. The firstfloor roof and beams are mainly transferred from the purlins to the first-floor Dou-gong brackets and then to the columns. It is a vulnerable part of the entire building system. Therefore, this article mainly discusses the load on the Dou-Gong brackets and the internal force of related components. In this way, the load transmission path and the weak points of the wooden members are analyzed to provide data support for protection and repair. 


\section{CALCULATION OF THE FIRST-FLOOR DOU-GONG BRACKETS}

\subsection{Determination of the Grade of Mirror Terrace According to Size of Dou-Gong Brackets}

The Dou-gong bracket on the first floor of the Mirror Terrace is a one jump bracket (Fig. 3) with a width of 90 $\mathrm{mm}$ and a height of $156 \mathrm{~mm}$. The Song dynasty units are used in YingzaoFashi.

Mirror Terrace is closest to the YingzaoFashi eighth grade, so the eighth grade is used for the Mirror Terrace.

According to the Engineering Practice in the Qing dynasty Dou-Gong on columns on the first story of the Mirror Terrace was analyzed using the Dou-K'ou system (Fig. 4).

Combined with the Engineering Practice, the size of the Mirror Terrace Dou-Gong bracket on the column is between the seventh grade and eighth grade, combined with the YinggzaoFashi, the following will calculate the load according to the eighth grade in the calculation.

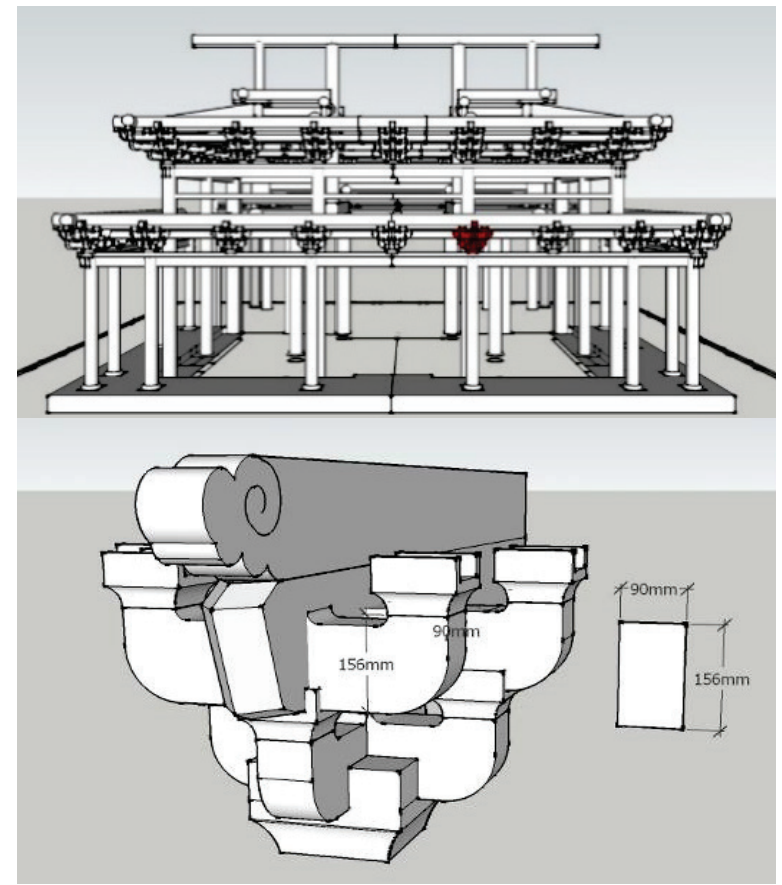

Figure 3 Dou-gong bracket on the first-floor

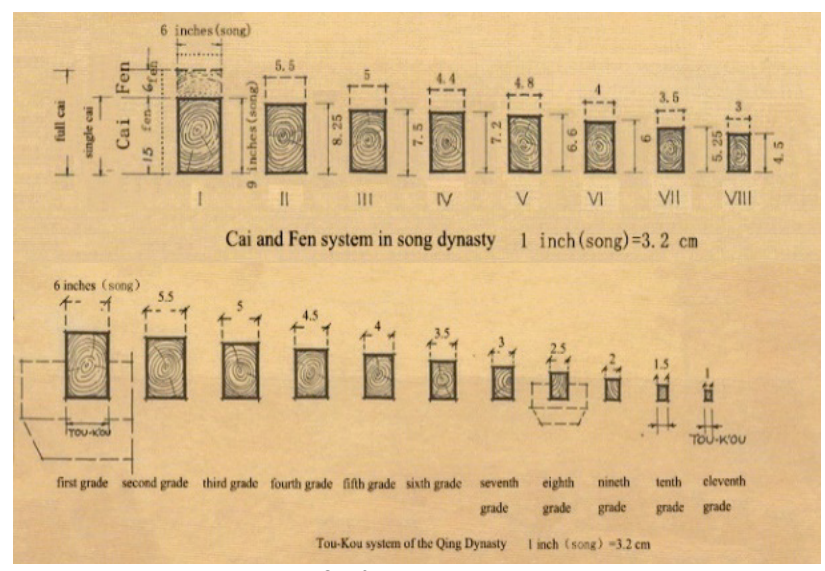

Figure 4 Cai fen and Tou-K'ou system

According to Tab. 6-2 from [10], converting the roof weight per square hundred parts of each grade into a roof, the weight of each tile combined with the round tile and flat tile is $3959.7 \mathrm{~kg}$ and the roof weight of the eight grade roof is $3.6 \mathrm{~kg}$ per square hundred. Therefore, when calculating the roof weight of the Mirror Terrace, 3959.7 Jin (Song dynasty) per square foot was taken for the calculation.

\subsection{Dead Weight of the Roof}

The roof is composed of tile, ridge, beast, etc. The tile surface is composed of tile, firewood stack, lime, bamboo fence, reed foil, purple clay, wheat bran, slab stack, etc [17].

Mirror Terrace Musical pavilion is the gable and hip double-eaves. It can be seen that the entire weight of the roof of the first floor is transmitted by the Dou-Gong brackets and the weight of the second-floor roof is transmitted to the pillars in the wall of the pavilion through the second floor Dou-Gong brackets. But the first-floor Dou-Gong brackets also bear the weight of the part of the second-floor roof. This part of the force is relatively small and difficult to estimate. This part of the force is omitted in the calculation process. Therefore, the first-floor DouGong brackets are mainly subjected to the entire weight of the first-floor eave.

All units used in the construction method are Song Dynasty units. Units need to be converted before calculation.

$1 \mathrm{~kg} \approx 1.6$ Jin (Song dynasty);

1 meter $\approx 3.125$ foot (Song dynasty);

1 square Zhang (Chinese unit) $=10.24$ square meters.

According to the above mentioned Mirror Terrace roof weight, take 3959.7 Jin (Song dynasty) calculation per square foot, converted into modern units is $246.59 \mathrm{~kg} / \mathrm{m}^{2}$.

Calculate the weight of the first-floor roof of Musical Pavilion, and consider the second-floor roof as a rectangular frame.

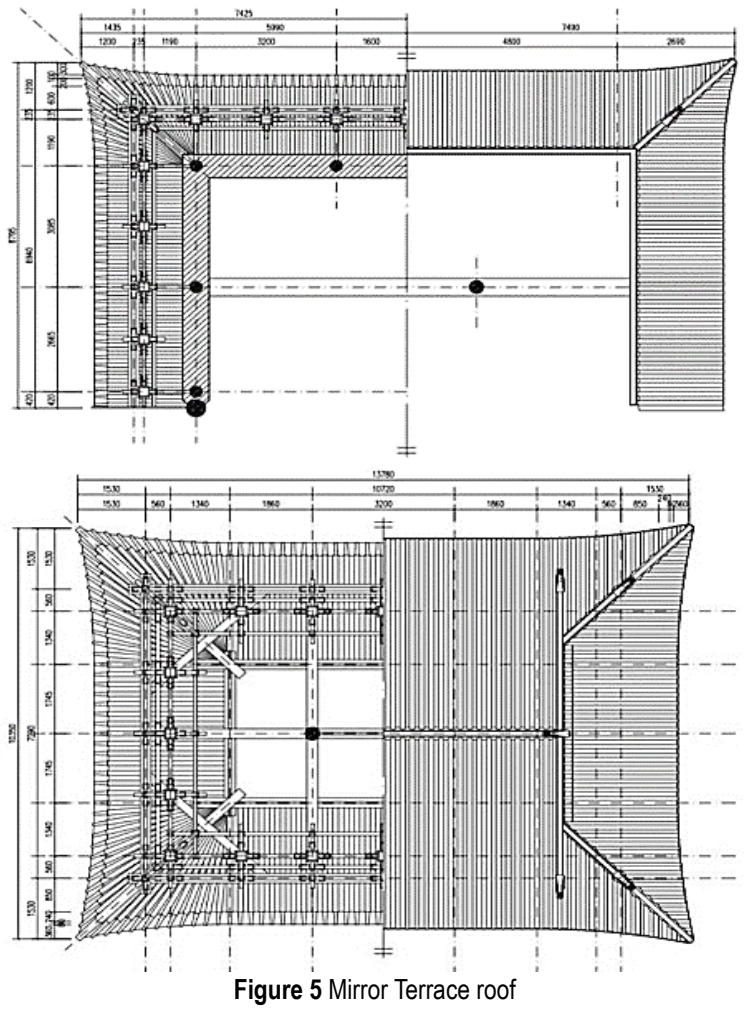

Technical Gazette 27, 5(2020), 1638-1647 
$S=\left(a \cdot h-a_{\text {middle }} \cdot h_{\text {middle }}\right) / \cos 35^{\circ}=87.83 \mathrm{~m}^{2}$

Based on the weight per square meter of the roof of Musical Pavilion, calculated from the previous paragraph, the total weight of the roof of Musical Pavilion on the first floor is:

$W_{\text {total }}=87.83 \mathrm{~m}^{2} \cdot 246.59 \mathrm{~kg} / \mathrm{m}^{2}=21658 \mathrm{~kg}$

\subsection{Timber Frame Weight}

As shown in Fig. 3, the red part is the research object of the Dou-Gong brackets. The gravity of the two-story beam frame is transmitted to the hypostyle column through the Dou-Gong bracket on the hypostyle column. However, the Dou-Gong bracket on the peristyle column of the first floor is hardly subjected to the pressure of the second-floor beam. Therefore, when calculating the gravity of the DouGong bracket on the peristyle column of the first floor, the main consideration is the load generated by the first-floor roof.

The first-floor roof load:

The weight of the wood is 770 Jin (Song dynasty) $/ \mathrm{m}^{3}$, converted into $481.25 \mathrm{~kg} / \mathrm{m}^{3}$. The volume of the square purlin(Fei) is $0.083 \mathrm{~m}^{3}$. And the weight of the square purlin(Fei) is $39.94 \mathrm{~kg}$. The weight of the square purlin received by the Dou-Gong bracket is $1554 \mathrm{~mm}$. The weight of the square purlin is $5.14 \mathrm{~kg}$. The volume of purlin is $0.649 \mathrm{~m}^{3}$. And the weight of purlin is $312.33 \mathrm{~kg}$. The weight of the purlins received by the Dou-Gong bracket is $1554 \mathrm{~mm}$. The weight of the purlin is:

$$
312.33 \mathrm{~kg} \cdot 1554 \mathrm{~mm} / 13226 \mathrm{~mm}=36.70 \mathrm{~kg}
$$

Therefore, The Dou-Gong bracket on the peristyle column bears the weight of the wooden frame (WF):

$W_{\mathrm{WF}}=5.14 \mathrm{~kg}+36.70 \mathrm{~kg}=41.84 \mathrm{~kg}$, and the gravity is $0.4184 \mathrm{kN}$.

Table 1 Statistics of tiles for water mirro

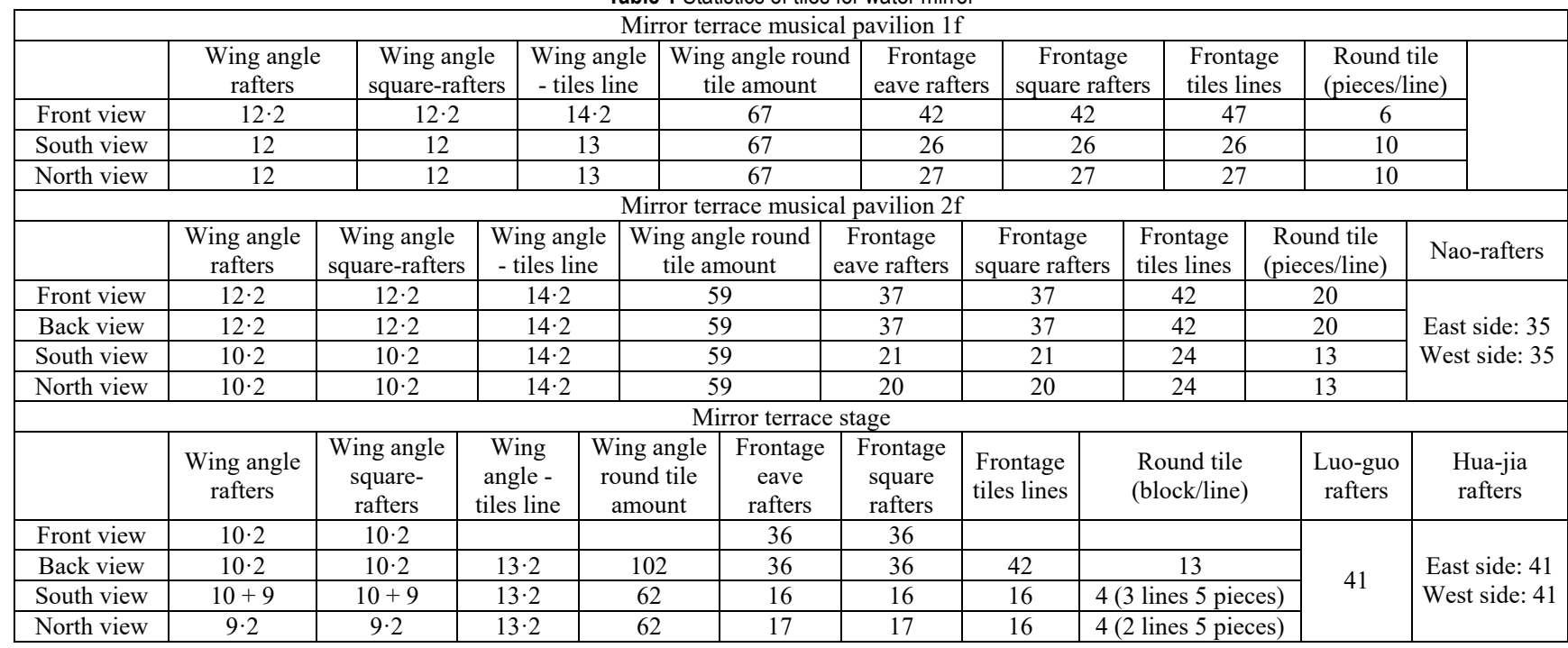

From statistics (Tab. 1), one can see the number of square rafters (Fei) and rafters on the Musical Pavilion side face. Frontage eave rafters are $100 \mathrm{~mm}$ in diameter, with a length of $2229 \mathrm{~mm}$. Square rafters are $70 \mathrm{~mm}$ in width, with a length of $900 \mathrm{~mm}$.

The volume of the rafter is $0.017 \mathrm{~m}^{3}$; The weight of the rafter is $8.18 \mathrm{~kg}$; The volume of the square rafter is 0.0044 $\mathrm{m}^{3}$; The weight of the square rafter is $W_{\mathrm{SR}}=2.12 \mathrm{~kg}$.

There are about 7 rafters and 7 square rafters in the load range of the first-floor eaves Dou-Gong bracket. The total calculated weight is $72.1 \mathrm{~kg}$ and the gravity is 0.721 $\mathrm{kN}$.

\subsection{Live Load}

The ancient building's live load is $0.3 \mathrm{kN} / \mathrm{m}^{2}$. According to the Specifications [18], the basic snow pressure reappearance period of the ancient building is 100 years and the basic snow pressure is $0.4 \mathrm{kN} / \mathrm{m}^{2}$. The wind pressure is $0.45 \mathrm{kN} / \mathrm{m}^{2}$. Live load plus wind load; wind load plus snow load. The most disadvantageous case is $0.85 \mathrm{kN} / \mathrm{m}^{2}$.

\subsection{Load Range}

As shown in Fig. 6, the red square represents the subject's first-floor Dou-Gong bracket. The gray area is the Dou-Gong bracket's load zone.

The actual area $(\mathrm{AC})$ is:

$S_{A C}=3200 \mathrm{~mm} \cdot 2671 \mathrm{~mm} / \cos 35^{\circ}=$

$=8547200 \mathrm{~mm}^{2} / \cos 35^{\circ}=8.55 \mathrm{~m}^{2}$

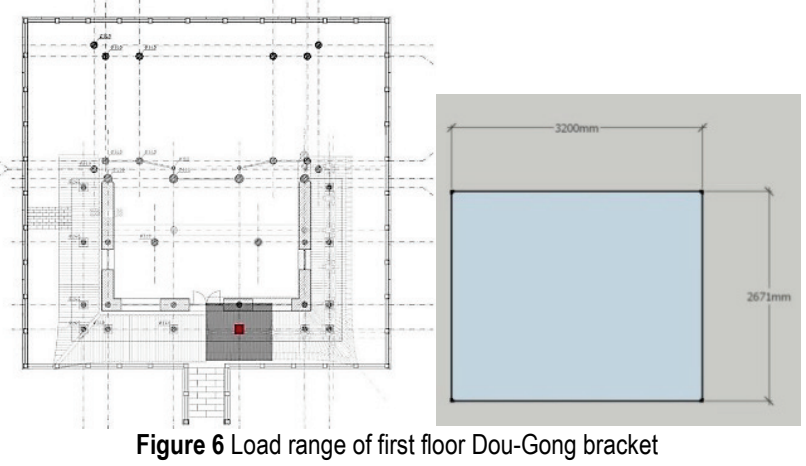




\subsection{Load Calculation}

The total load is calculated as the roof load plus timber frame dead weight plus live load:

$W_{\text {total }}=W_{\text {tile roof }}+W_{\text {wood structure }}+W_{\text {live }}$

$=246.59 \mathrm{~kg} / \mathrm{m}^{2} \cdot 10.44 \mathrm{~m}^{2}+41.84 \mathrm{~kg}+72.1 \mathrm{~kg}+$

$+85 \mathrm{~kg} / \mathrm{m}^{2} \cdot 10.44=3575.74 \mathrm{~kg}$, the gravity is $35.76 \mathrm{KN}$

\section{ANALYSIS OF STATIC STABILITY OF THE FIRST- FLOOR DOU-GONG BRACKETS}

\subsection{Calculation of the Internal Force and Stiffness of the Purlin under the Eaves}

The eaves load is mainly supported by the purlin under the eaves and the load is transmitted to the set on columns and the intermediate set. The load on the eaves is uniformly distributed. The purlin under the eaves on the column set is used as an example for calculation. The distance between the sets on columns and the intermediate sets is $1600 \mathrm{~mm}$. That is, the purlin under the eaves can be simplified into a simply supported beam with a length of $1600 \mathrm{~mm}$ and the uniformly distributed load is transmitted to the purlins.

The weight per square meter of the roof is 246.59 $\mathrm{kg} / \mathrm{m}^{2}$, that is, the gravity per square meter is 2465.9 $\mathrm{N} / \cos 35^{\circ}$. According to calculation, the uniformly distributed load on the purlin can be calculated as $q=8.04$ $\mathrm{N} / \mathrm{mm}$.

Assuming that the supports on both sides are Support A and Support B, respectively, calculate the reaction force of the support:

$Y_{\mathrm{A}}=Y_{\mathrm{B}}=\frac{1}{2} q l=\frac{8.04 \mathrm{~N} / \mathrm{mm} \times 1600 \mathrm{~mm}}{2}=6432 \mathrm{~N}$

Shear force at the support:

$V_{\mathrm{A}}=V_{\mathrm{B}}=\frac{1}{2} q l=\frac{8.04 \mathrm{~N} / \mathrm{mm} \times 1600 \mathrm{~mm}}{2}=6432 \mathrm{~N}$

Center bending moment:

$M_{\mathrm{O}}=\frac{1}{8} q l^{2}=\frac{8.04 \mathrm{~N} / \mathrm{mm} \times(1600 \mathrm{~mm})^{2}}{8}=2572800 \mathrm{Nmm}$

Simply supported beam under the effect of uniformly distributed load, the maximum deflection of the beam is in the middle, then the central deflection of the purlin is:

$$
E=14345 \mathrm{MPa}=14345 \mathrm{~N} / \mathrm{mm}^{2}
$$

$J=\frac{\pi \cdot d^{4}}{64}=\frac{\pi \cdot 250 \mathrm{~mm}^{4}}{64}=191747598.5 \mathrm{~mm}^{4}$

$Y_{\max }=\frac{5 q l^{4}}{384 E J}=\frac{5 \cdot(8.04 \mathrm{~N} / \mathrm{mm}) \cdot(1600 \mathrm{~mm})^{4}}{384 \cdot 14345 \mathrm{~N} / \mathrm{mm}^{2} \cdot 191747598.5 \mathrm{~mm}^{4}} \approx$ $\approx 0.25 \mathrm{~mm}$

Relative deflection: $\frac{f}{l}=\frac{0.25}{1600}=\frac{1}{6400}$

Relative deflection is far less than $1 / 150$ of modern wooden structure code.

\subsection{The Calculation of the Internal Force of the Plate and Lintel}

The plate and lintel are considered as a whole and an intermediate set is added to it. The plate and the lintel are both a beam between columns and have the function of bending. The intermediate set coordinating the purlin the lintel and the plate shares the eaves load. Their respective shapes are different and their bending resistances are also different. There are no similar structures in modern architecture and only mechanical principles are used to find the internal force and load of the component.

The plate and lintel are considered as a whole and the distance between the columns is $3200 \mathrm{~mm}$, which is simplified as a simply supported beam with a concentrated load length of $3200 \mathrm{~mm}$.

Calculation of the reaction force of the support:

$P=P_{\text {eave }}+P_{\text {intermediate set }}$

$17.88 \mathrm{kN}+0.54 \mathrm{kN}=18.42 \mathrm{kN}=18420 \mathrm{~N}$

$Y_{\mathrm{A}}=Y_{\mathrm{B}}=\frac{1}{2} P=\frac{18420 \mathrm{~N}}{2}=9210 \mathrm{~N}$

Shear force at the support:

$V_{\mathrm{A}}=V_{\mathrm{B}}=9210 \mathrm{~N}$

Center Bending moment:

$M_{\mathrm{O}}=\frac{1}{4} P l=\frac{18420 \mathrm{~N} \times 3200 \mathrm{~mm}}{4}=14736000 \mathrm{Nmm}$

Under the action of concentrated load, the maximum deflection of the simply supported beam is in the mid-span, then the center deflection of the plate is:

$E=14345 \mathrm{MPa}=14345 \mathrm{~N} / \mathrm{mm}^{2}$

$J=\frac{b h^{3}}{12}=\frac{200 \mathrm{~mm} \cdot(85 \mathrm{~mm})^{3}}{12}=10235417 \mathrm{~mm}^{4}$

$Y_{\max }=\frac{p l^{3}}{48 E J}=\frac{18420 \mathrm{~N} \cdot(3200 \mathrm{~mm})^{3}}{48 \cdot 14345 \mathrm{~N} / \mathrm{mm}^{2} \cdot 10235417 \mathrm{~mm}^{4}} \approx$

$\approx 85.64 \mathrm{~mm}$

Relative deflection:

$\frac{f}{l}=\frac{85.64}{3200}=\frac{1}{37}$

Relative deflection is greater than $1 / 150$ of modern wooden structure code.

Under the action of concentrated load, the maximum 
deflection of the simply supported beam is in the span, so the central deflection of the lintel is:

$E=14345 \mathrm{MPa}=14345 \mathrm{~N} / \mathrm{mm}^{2}$

$J=\frac{b h^{3}}{12}=\frac{70 \mathrm{~mm} \cdot(220 \mathrm{~mm})^{3}}{12}=62113333 \mathrm{~mm}^{4}$

$Y_{\max }=\frac{p l^{3}}{48 E J}=\frac{18420 \mathrm{~N} \cdot(3200 \mathrm{~mm})^{3}}{48 \cdot 14345 \mathrm{~N} / \mathrm{mm}^{2} \cdot 62113333 \mathrm{~mm}^{4}} \approx$

$\approx 14.11 \mathrm{~mm}$

Relative deflection:

$\frac{f}{l}=\frac{14.11}{3200}=\frac{1}{227}$

Relative deflection is less than $1 / 150$ of the modern wooden structure code.

It can be seen that the lintel and the plate as a whole are under the action of concentrated load. The seat shear force and bending moment are both larger than the rafter and the bending moment is at the center. Therefore, the position between the two columns of the plate is subjected to the largest bending. Then analyzing its stiffness, one can see that the rafter under the eave's deflection is very small. The relative deflection is far lower than $1 / 150$ of the wooden structure code, so it is difficult to have bending deformation. From a mechanical point of view, there is a waste of materials. The plate deflection is relatively high and the relative deflection exceeds the modern wooden structure code of $1 / 150$. The high deflection is prone to bending deformation. The deflection of the lintel is lower than that of the plate. Therefore, the bending will be transmitted down to the lintel to resist the bending deformation together. From the relative deflection value, the plate and the lintel are regarded as the overall value, which is less than the modern wooden structure specification value. From actual observation, the lintel bending between the two pillars is already visible to the eyes. Due to the age of the ancient building, its wood properties changed with time. So it is only a reference standard that relative deflection value does not exceed the wooden structure code. When the maximum deflection is relatively large, it indicates that this part belongs to the weaker part of the entire wooden frame. In the case of obvious bending or tensile crack at the base of the lintel, repair measures should be taken in time.

\section{CALCULATION OF THE SECOND-FLOOR DOU-GONG BRACKETS}

The shape of the two-story Dou-Gong on a column is shown in Fig. 7 and the width and height of the Dou-Gong are measured. The vertical load on the second-floor DouGong bracket includes three parts: the roof own weight, the timber frame's own weight and the live load.

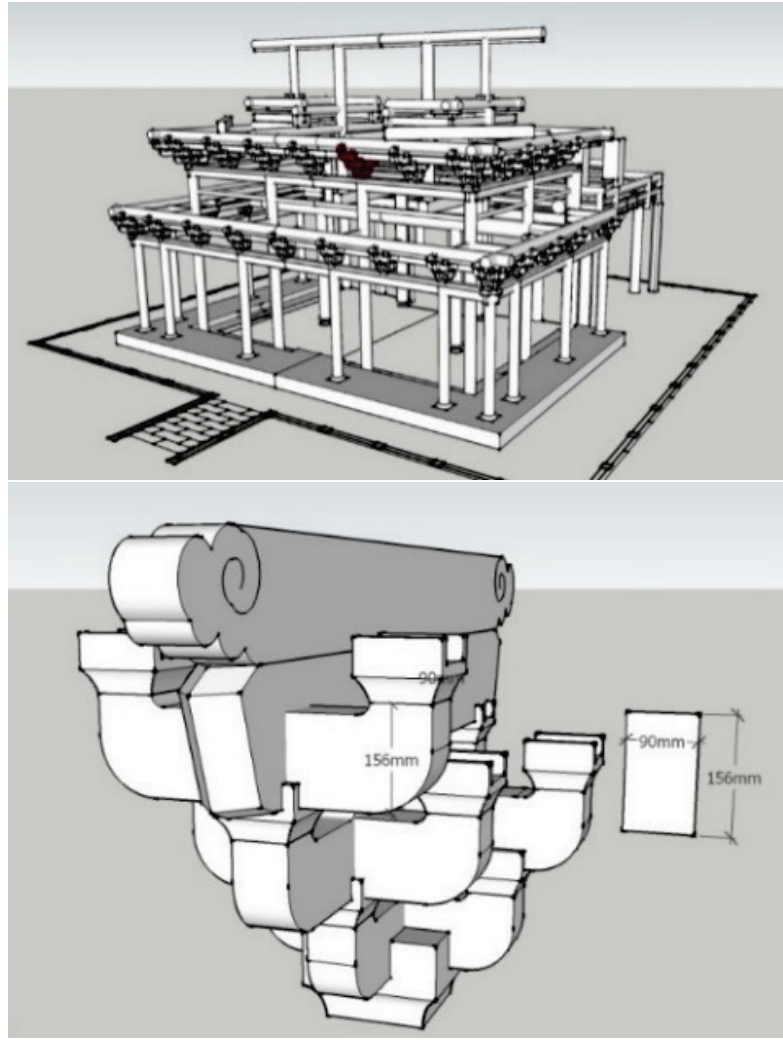

Figure 7 Dou-gong bracket on the second-floor.

\subsection{Roof Self-Weight}

The inclination angle of the roof tile is calculated as $35^{\circ}$. Firstly, the total area of the second-floor roof of Musical Pavilion was calculated. If the projected area of the roof is approximately rectangular (Fig. 6), the actual area is:

$S=a \cdot h / \cos 35^{\circ}=13780 \mathrm{~mm} \cdot 10350 \mathrm{~mm} / \cos 35^{\circ}=$

$=142623000 \mathrm{~mm}^{2} / \cos 35^{\circ}=174.111 \mathrm{~m}^{2}$

According to the weight per square meter of the Mirror Terrace Musical Pavilion roof calculated from the previous paragraph, the total weight of the second-floor roof (SFR) of Musical Pavilion is:

$W_{\mathrm{SFR}}=174.111 \mathrm{~m}^{2} \cdot 246.59 \mathrm{~kg} / \mathrm{m}^{2}=42934 \mathrm{~kg}$

\subsection{Timber Frame Weight}

The timber frame is the load-bearing structure of the house. The wood has lightweight; however, due to the large amount, its own weight can also affect the internal force of the component [19]. Therefore, it is also included in the calculation of the load. The weight of the wood is 481.25 $\mathrm{kg} / \mathrm{m}^{3}$.

\subsubsection{Rafter, Square Rafter (Fei)}

The rafter is a bending member on the purlin and the angle between the rafter and the horizontal plane is $25-45^{\circ}$. The number of rafters is shown in Tab. 1. The second-floor rafter has a diameter of $120 \mathrm{~mm}$, a length of $3000 \mathrm{~mm}$, square rafter has a width of $90 \mathrm{~mm}$ and a length of 1220 $\mathrm{mm}$. 
Rafter $(R)$ volume and weight are:

$V_{\mathrm{R}}=\pi \cdot r^{2} \cdot l=0.034 \mathrm{~m}^{3} ; W_{\mathrm{R}}=16.36 \mathrm{~kg}$

Square rafter (Fei) volume and weight is:

$V_{\mathrm{SR}}=b h l=9882000 \mathrm{~mm}^{3}=0.01 \mathrm{~m}^{3}$

$W_{\mathrm{SR}}=4.81 \mathrm{~kg}$

Wing angle rafters have different lengths, which can be regarded as the length of frontage eave rafters, and the length of Nao rafters is the same as that of the frontage eave rafters. Therefore, the number of rafters is:
To the front facade 96; the back facade 96; the south side 45 ; the north side 44 . The total number of rafters is 281 ; the total weight is $281 \times 16.36=4597.16 \mathrm{~kg}$.

The total weight of square rafters (Fei) is $976.43 \mathrm{~kg}$.

The total weight of rafters and square rafters (Fei) is $5573.59 \mathrm{~kg}$.

\subsubsection{Purlin, Square Purlin (Fei)}

Fig. 8 shows distribution of the two-story wooden frame of the Mirror Terrace.

In Tab. 2, the volume and weight of Musical building purlins and square purlins are shown.

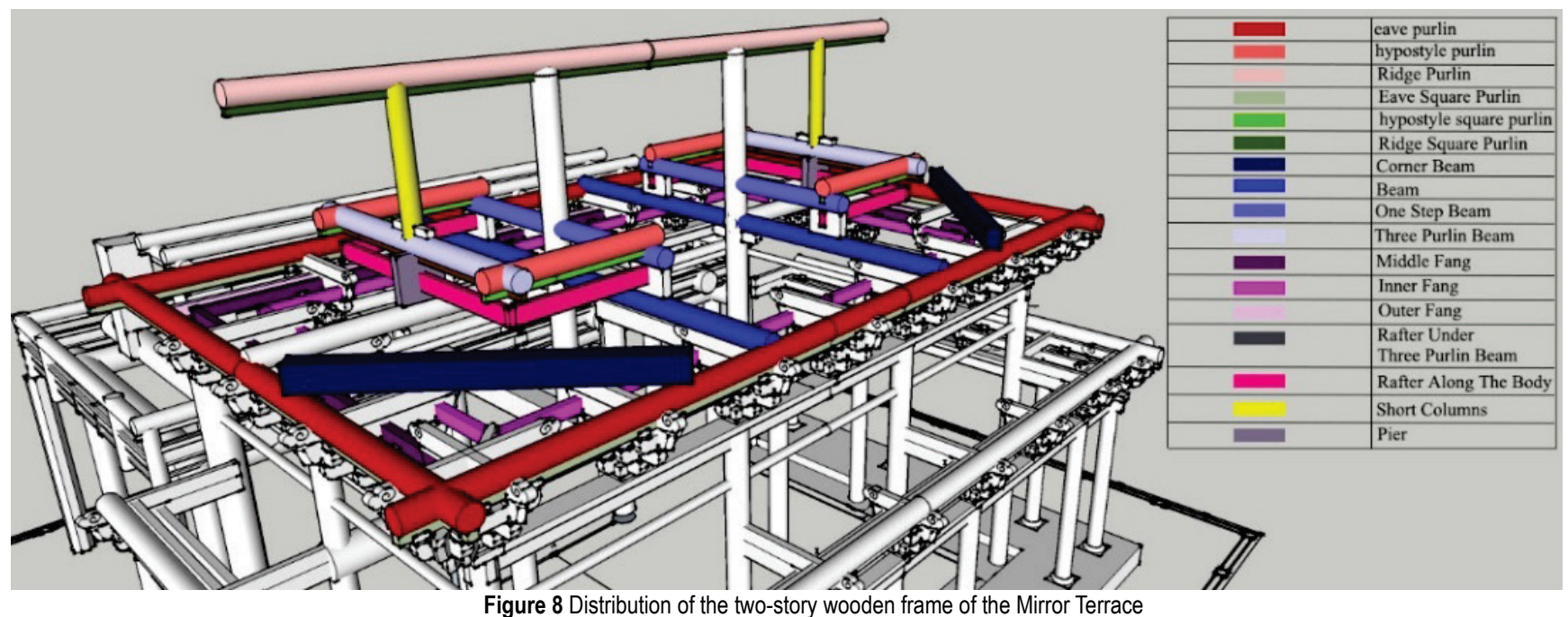

Table 2 Volume and weight of Purlins and square purlins

\begin{tabular}{|c|c|c|c|c|c|c|c|c|}
\hline \multicolumn{2}{|r|}{ Type } & Quantity & $\begin{array}{l}\text { Width(diameter) } \\
/ \mathrm{mm}\end{array}$ & $\begin{array}{l}\text { Height } \\
/ \mathrm{mm}\end{array}$ & $\begin{array}{l}\text { Length } \\
/ \mathrm{mm}\end{array}$ & $\begin{array}{l}\text { Volume } \\
/ \mathrm{m}^{3}\end{array}$ & $\begin{array}{c}\text { Total volume } \\
/ \mathrm{m}^{3}\end{array}$ & $\begin{array}{c}\text { Total weight } / \mathrm{kg} \\
\left(481.25 \mathrm{~kg} / \mathrm{m}^{3}\right)\end{array}$ \\
\hline \multirow{4}{*}{ Purlin } & Eave purlin (east-west) & 2 & 125 & & 11520 & 0.565 & 1.130 & 543.81 \\
\hline & Eave purlin (north-south) & 2 & 125 & & 7295 & 0.360 & 0.720 & 346.50 \\
\hline & Hypostyle purlin & 4 & 125 & & 2245 & 0.110 & 0.440 & 211.75 \\
\hline & Ridge purlin & 1 & 125 & & 10278 & 0.504 & 0.504 & 242.55 \\
\hline \multirow{4}{*}{ Square purlin } & Eave purlin (east-west) & 2 & 90 & 80 & 11520 & 0.083 & 0.166 & 79.89 \\
\hline & Eave purlin (north-south) & 2 & 90 & 80 & 8065 & 0.058 & 0.116 & 55.83 \\
\hline & Hypostyle purlin & 4 & 60 & 80 & 2245 & 0.011 & 0.044 & 21.18 \\
\hline & Ridge purlin & 1 & 80 & 90 & 10278 & 0.074 & 0.074 & 35.61 \\
\hline & Summation & 18 & & & & & 3.194 & 1537.1 \\
\hline
\end{tabular}

Table 3 Volume and weight of Fang

\begin{tabular}{|c|c|c|c|c|c|c|c|}
\hline Type & Quantity & Width / mm & Height / mm & Length / mm & Volume / $\mathrm{m}^{3}$ & Total volume $/ \mathrm{m}^{3}$ & $\begin{array}{c}\text { Total weight } / \mathrm{kg} \\
\left(481.25 \mathrm{~kg} / \mathrm{m}^{3}\right)\end{array}$ \\
\hline Middle fang(east-west) & 2 & 90 & 156 & 11104 & 0.156 & 0.312 & 150.150 \\
\hline Middle fang(north-south) & 2 & 90 & 156 & 6266 & 0.088 & 0.176 & 84.700 \\
\hline Outer fang(east-west) & 2 & 90 & 156 & 11662 & 0.164 & 0.328 & 157.850 \\
\hline Outer fang(north-south) & 2 & 90 & 156 & 6825 & 0.096 & 0.192 & 92.400 \\
\hline Inner fang(east-west) & 2 & 90 & 156 & 9984 & 0.140 & 0.280 & 134.750 \\
\hline Inner fang(north-south) & 2 & 90 & 156 & 5145 & 0.072 & 0.144 & 69.300 \\
\hline RATB(east-west) & 4 & 70 & 210 & 1760 & 0.026 & 0.104 & 50.050 \\
\hline RATB(north-south) & 2 & 70 & 210 & 3420 & 0.050 & 0.100 & 48.125 \\
\hline Summation & 18 & & & & & 1.636 & 787.325 \\
\hline
\end{tabular}

Table 4 Volume and weight of Beams, Columns and Piers

\begin{tabular}{|c|c|c|c|c|c|c|c|c|}
\hline Type & Quantity & Width / mm & Height / mm & Length / mm & Volume $/ \mathrm{m}^{3}$ & Total volume / $\mathrm{m}^{3}$ & $\begin{array}{c}\text { Total weight } / \mathrm{kg} \\
\left(481.25 \mathrm{~kg} / \mathrm{m}^{3}\right)\end{array}$ & Type \\
\hline \multirow{4}{*}{ Beam } & Beam & 2 & 125 & & 7295 & 0.360 & 0.720 & 346.50 \\
\hline & Three purlin beam & 2 & 125 & & 4030 & 0.198 & 0.396 & 190.58 \\
\hline & One step beam & 2 & 125 & & 4030 & 0.198 & 0.396 & 190.58 \\
\hline & Corner beam & 2 & 200 & 300 & 3700 & 0.222 & 0.444 & 213.68 \\
\hline \multicolumn{2}{|r|}{ Short column } & 2 & 110 & & 1685 & 0.064 & 0.128 & 61.60 \\
\hline \multicolumn{2}{|r|}{ Pier } & 2 & 120 & 540 & 580 & 0.0376 & 0.075 & 36.19 \\
\hline \multicolumn{2}{|r|}{ Summation } & 12 & & & & & 2.159 & 1039.13 \\
\hline
\end{tabular}




\subsubsection{Fang}

In Tab. 3, the volume and weight of Musical Building Fangs are shown.

\subsubsection{Beams, Columns, Piers}

In Tab. 4, the volume and weight of Musical Building Beams, Columns and Piers are shown.

\subsection{Load Range}

As shown in Fig. 9, the total area of the roof is 143.296 $\mathrm{m}^{2}$. The loading area is $15.408 \mathrm{~m}^{2}$.

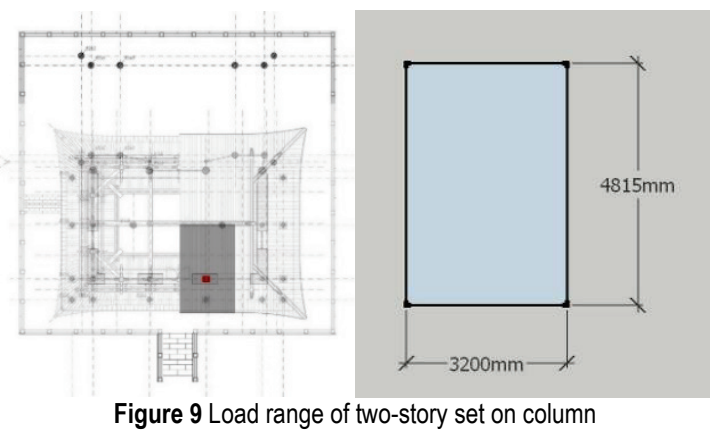

\subsection{Calculation of the Second-Floor Set on Column's Load}

The second-floor total load is the roof's own weight, the timber frame's own weight and live load.

The weight of a wooden frame is the total weight of rafters, square rafters, purlins, square purlins, Fangs, beams, columns.

$W_{\text {total }}=5573.59+1537.1+787.325+1039.13=$ $=8937.145 \mathrm{~kg}$.

The self-weight of the roof (SOTR) supported by the set on a column of the second-floor is:

$W_{\text {SOTR }}=42934 \cdot 15.408 / 143.296=4,616.51 \mathrm{~kg}$.

The weight of the wooden frame (WOTWF) on second-floor is:

$W_{\text {WOTWF }}=8937.145 \cdot 15.408 / 143.296=960.97 \mathrm{~kg}$.

The total weight (TW) of the second-floor supported by the set on the column is:

$W_{\mathrm{TW}}=4616.51+960.97=5577.48 \mathrm{~kg}$.

That is to say, the gravity of the second-floor, supported by the set on the column, is $55.77 \mathrm{kN}$. The live load of ancient buildings is $0.85 \mathrm{kN} / \mathrm{m}^{2}$. The live load on the second-floor supported by the set on the column is:

$0.85 \mathrm{~kg} / \mathrm{m}^{2} \cdot 15.408 \mathrm{~m}^{2} / \cos 35=15.99 \mathrm{kN}$.

Then the second-floor DouGong bracket (DB) load is:

\section{ANALYSIS OF STATIC STABILITY OF THE SECOND- FLOOR DOU-GONG BRACKETS}

6.1 Calculation of the Internal Force and Stiffness of the Eave Purlins

The two-story eaves can be simplified as a simply supported beam with a length of $1600 \mathrm{~mm}$ and the uniformly distributed load is transmitted on it. According to the calculation above, it can be seen that the load of the second-floor DouGong bracket is $71.76 \mathrm{kN}$. After calculation, the uniformly distributed load of the secondfloor eaves can be obtained $q=22.43 \mathrm{~N} / \mathrm{mm}$

Assume that the supports on both sides are Support A and Support B. Refer to the previous section to calculate the reaction force of its support. It is $17944 \mathrm{~N}$; Shear force at the support is $17944 \mathrm{~N}$; Center bending moment is $7177600 \mathrm{~N} \cdot \mathrm{mm}$.

Under the action of uniformly distributed beams, the maximum deflection of the simply supported beam is in the mid-span.

$E=14345 \mathrm{MPa}=14345 \mathrm{~N} / \mathrm{mm}^{2}$

$J=\frac{\pi \cdot d^{4}}{64}=\frac{\pi \cdot 250 \mathrm{~mm}^{4}}{64}=191747598.5 \mathrm{~mm}^{4}$

$Y_{\max }=\frac{5 q l^{4}}{384 E J}=\frac{5 \cdot(22.43 \mathrm{~N} / \mathrm{mm}) \cdot(1600 \mathrm{~mm})^{4}}{384 \cdot 14345 \mathrm{~N} / \mathrm{mm}^{2} \cdot 191747598.5 \mathrm{~mm}^{4}} \approx$ $\approx 0.69 \mathrm{~mm}$

Relative deflection:

$\frac{f}{l}=\frac{0.69}{1600}=\frac{1}{2319}$

The relative deflection is far less than $1 / 150$ of the modern wooden structure code, and it is not easy to bend.

\subsection{Calculation of Plate and Lintel Internal Force}

The plate and lintel are considered as a whole and the distance between the eaves columns is $3200 \mathrm{~mm}$, which is simplified as a simply supported beam with a concentrated load length of $3200 \mathrm{~mm}$.

Calculation of support reaction force:

$P=P_{\text {eave }}+P_{\text {intermidiate set }}$

$35.88 \mathrm{kN}+0.856 \mathrm{kN}=36.736 \mathrm{kN}=36736 \mathrm{~N}$

$Y_{\mathrm{A}}=Y_{\mathrm{B}}=\frac{1}{2} P=\frac{36736 \mathrm{~N}}{2}=18.368 \mathrm{~N}$

Shear force at the support is $18368 \mathrm{~N}$; Center bending moment is $29388800 \mathrm{~N} \cdot \mathrm{mm}$.

Under the action of concentrated loads, the maximum deflection of the simply supported beam is in the mid-span, so the central deflection of the plate is [20]:

$E=14345 \mathrm{MPa}=14345 \mathrm{~N} / \mathrm{mm}^{2}$

$W_{\mathrm{DB}}=55.77 \mathrm{kN}+15.99 \mathrm{kN}=71.76 \mathrm{kN}$. 
$J=\frac{b h^{3}}{12}=\frac{290 \mathrm{~mm} \cdot(85 \mathrm{~mm})^{3}}{12}=14841354 \mathrm{~mm}^{4}$

$Y_{\max }=\frac{p l^{3}}{48 E J}=\frac{36736 \mathrm{~N} \cdot(3200 \mathrm{~mm})^{3}}{48 \cdot 14345 \mathrm{~N} / \mathrm{mm}^{2} \cdot 14841354 \mathrm{~mm}^{4}} \approx$

$\approx 117 \mathrm{~mm}$

Relative deflection:

$\frac{f}{l}=\frac{117}{3200}=\frac{1}{27}$

Relative deflection is greater than $1 / 150$ of modern wooden structure code

Under the action of concentrated load, the maximum deflection of the simply supported beam is in the mid-span, so the central deflection of the lintel is:

$E=14345 \mathrm{MPa}=14345 \mathrm{~N} / \mathrm{mm}^{2}$

$J=\frac{b h^{3}}{12}=\frac{90 \mathrm{~mm} \cdot(220 \mathrm{~mm})^{3}}{12}=79860000 \mathrm{~mm}^{4}$

$Y_{\max }=\frac{p l^{3}}{48 E J}=\frac{36621 \mathrm{~N} \cdot(3200 \mathrm{~mm})^{3}}{48 \cdot 14345 \mathrm{~N} / \mathrm{mm}^{2} \cdot 79860000 \mathrm{~mm}^{4}} \approx$

$\approx 22 \mathrm{~mm}$

Relative deflection:

The relative deflection is slightly greater than $1 / 150$ of the modern timber structure code.

\section{DISCUSSION}

Under the action of concentrated load on the secondfloor, the lintel and the plate as a whole have higher support shear and bending moments than the eave purlin, especially the bending moment in the center, so the position between the two columns of the plate is the largest. After analyzing its stiffness, it can be seen that the deflection value of the second-floor eave purlin is greater than that of the first floor, but it is still far lower than $1 / 150$ of the wooden structure specification, so it is difficult to cause the bending deformation. The plate deflection value is high. Due to the large load, the relative deflection is larger than that of the first floor. It can be seen that the plate deflection moment is large and the deflection value is high so the bending deformation is easy to occur. The lintel deflection value below is lower than that of the plate, so the bending will be transmitted down to the lintel, which will jointly resist the bending deformation.

During the calculation process, it is found that the size of the second-floor lintel and the plate was adjusted compared to the first tier, as shown in Fig. 10. If the second floor still uses the dimensions of the plate and lintel of the first floor, it is concluded that the relative value of the overall deflection is greater than the standard value and its structure will be easily damaged. After adjusting to the actual size of the second floor, the relative deflection value will be slightly less than the standard. Between the two- story columns, square purlins are added to the lower part of the lintel to enhance the connection between the columns. At the same time, they can also resist some bending moments. Simultaneously the diameter of the column is increased from $240 \mathrm{~mm}$ to $280 \mathrm{~mm}$ in the diameter of the lower column of the Dou-Gong brackets, so as to better support the vertical loads. From the relative deflection value, the plate and the lintel as a whole are slightly smaller than the modern wooden structure specification value.

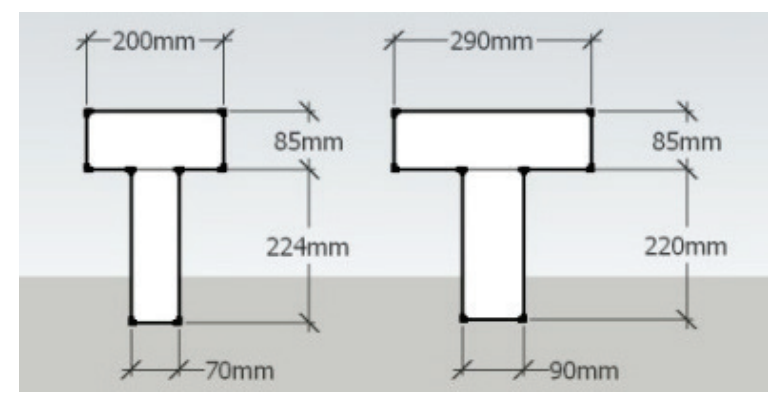

Figure 10 Sectional view of the first and second frontal ridges

Considering the changes in the properties of the wood, the middle position between the lintel and the plate will be a part that is prone to bend and cause the structural damage. It needs to be monitored and maintained.

\section{CONCLUSIONS}

1. It was calculated that the load on the first floor DouGong bracket is $35.76 \mathrm{kN}$, and the second-floor Dou-Gong bracket is $71.53 \mathrm{kN}$. Similar buildings loads in the future can be calculated by reference

2. Since the roof weight is transmitted to the second floor Dou-Gong brackets through the pillar and then directly transferred to the column from the Dou-Gong brackets and directly to the bottom of the column without going through the first floor Dou-Gong brackets, the second-floor Dou-Gong brackets bear a higher load than the first floor.

3. After calculation of the internal force, it can be seen that because of its large sectional area, the eave rafters have a good ability to resist shear and bending, and are not prone to structural damage. The absolute value of the deflection of the lintel and plate is slightly larger than the standards. But there are already visible bends that need to be maintained.

The second-floor eave rafter is also prone to damage and the relative deflection of the lintel and the plate is between the standard thresholds, so it is vulnerable.

4. Through the basic mechanical analysis calculations, it can be seen that due to the large load of the second floor, the relative value of the maximum deflection in the middle of the lintel and plate is already within the threshold of the standard. Therefore, the sectional areas of the lintel and the plate are enlarged.

The square rafters connection was added between the columns and the diameter of the columns under the second floor Dou-Gong brackets was increased, which shows the wisdom of the craftsmen in building construction.

This study aims to provide useful reference considering the static stability for safety evaluation and preservation of cultural heritage. The findings of this study 
can help to estimate the load range of the wooden buildings in the Ming Dynasty and evaluate the static stability of the building to provide detailed information for the buildings maintenance and protection.

So far, only the load and the static stability of one example is calculated. each building has different features of static stability, with respect to the roof types, grades, dynasty of Chinese ancient buildings. A series of comprehensive tests and calculations is required to get better understanding of the Chinese wooden building static stability features and numerical law of the building load.

\section{Acknowledgments}

This research is supported by the project "Research on the Age and Structural Mechanics Characteristics of Jinci Mirror Terrace"; The authors would like to thank the Taiyuan Cultural Relic Protection Department and the JinCi Museum for the assistance provided during the onsite survey of the Mirror Terrace. Thanks are also due to the Shanxi Conservation of Historic Building Design Station for providing their valuable comments.

\section{REFERENCES}

[1] Liu, D. (2001). Load compilation of ancient building roofs. Ancient Garden Technology.

[2] The Code for Loads of Building Structures. BeiJing: China Construction Industry Press, 2012.

[3] Code for design of wooden structures. BeiJing: China Construction Industry Press, 2017.

[4] Dong, X. (2010). Analysis of load value of wooden structures in ancient buildings. Structural Engineer, 26(04), 42-46.

[5] Chen, Z., Zhu, E., Lam, F., \& Pan, J. (2014). Structural performance of Dou-Gong brackets of Yingxian Wood Pagoda under vertical load - An experimental study. Engineering Structures, 80, 274-288. https://doi.org/10.1016/j.engstruct.2014.09.013

[6] Meng, X., Li, T., \& Yang, Q. (2019).Experimental study on the seismic mechanism of a full-scale traditional Chinese timber structure. Engineering Structures, 180, 484-493. https://doi.org/10.1016/j.engstruct.2018.11.055

[7] Zhou, Q. \& Yan, W. (2012). Bending analysis on composite beam and combination beam of Chinese ancient wooden buildings. Building Structure, 42(04).

[8] Qiao, G., Li, T., \& Chen, Y. F. (2016). Assessment and retrofitting solutions for an historical wooden pavilion in China. Construction and Building Materials, 105, 435-447. https://doi.org/10.1016/j.conbuildmat.2015.12.107

[9] Zhou, Q., Yan, W., Guan, H., \& Ji, J. (2013). Construction for static stability of Taihe Palace in the Forbidden City. Journal of Shandong Architectural University.

[10] Wang, T. (1992). A Preliminary Study of the Statics of Ancient Wooden Works. BeiJing: Cultural relics Press.

[11] Wang, J., Dai, Z., Jia, S., Yu, H., \& Wei, H. (2017). Structural Analysis and Load Calculation of an Antique Building in a Shaolin Hall. China Science and Technology Information.

[12] Li, J., Yingc, Z., \& Fa, S. (1954). Shanghai. Business Press.

[13] Liang, S. (2006). Engineering Practice in the Qing dynasty. Beijing: Tsinghua University Press.

[14] Wang, X. (2019). On the Architectural Shape and Decoration Features of Jinci Water Mirror. Chinese cultural heritage, (01), 102-105.

[15] Dan, W. (2016). Wind load characteristics of roof of ancient Chinese architecture; Beijing Jiaotong University.

[16] Hao, Y. (2004). Mechanical study and seismic analysis of ancient wooden structures; Beijing Jiaotong University.

[17] Chen, W. (2006). Research on Large-scale Buildings during the Sui and Tang Dynasties - on Wu Zetian Mingtang, Fudan University.

[18] Technical specifications for maintenance and reinforcement of wooden structures in ancient buildings. Beijing: China Construction Industry, 1993.

[19] Ning, P. (2013). Study on the Mechanical Properties of Halltype Wooden Frames and Through-tenon Joints. Xiamen University.

[20] Zou, L. (2013). Engineering mechanics. WuHan, Huazhong University of Science and Technology Press.

\section{Contact information:}

\section{Chengya ZHANG}

College of Architecture,

Taiyuan University of Technology,

No. 79, Yingze Street, Taiyuan, 030024, Shanxi, China

\section{Yubo GAO}

(Corresponding author)

College of Architecture,

Taiyuan University of Technology,

No. 79, Yingze Street, Taiyuan, 030024, Shanxi, China

E-mail: ke.lefanfan@163.com

\section{Enze DUAN}

Shanxi Academy of Ancient Building and Paint Sculpture \& Fresco Preservation, No. 40, Wangcunbei Street, Taiyuan, 030012, Shanxi, China 